\title{
COLABORAN EN ESTE NUMERO
}

Manuel García-Pelayo y Alonso: Nació en Corrales (Zamora) en 1909. Doctor en Derecho por la Universidad de Madrid, estudió también en las de Viena y Berlín. Hasta 1936 estuvo encargado de la cátedra de Filosofía del Derecho en la Universidad de Madrid y desde 1952 profesó en Hispanoamérica, primero en Buenos Aires y más tarde en Puerto Rico y Caraces, donde fundó y dirigió el Instituto de Estudios Políticos de la Universidad Central de Venezuela, de la que es doctor honoris causa. Autor de numerosos trabajos y libros, entre los que destacan El imperio británico (1945), Derecho constitucional comparado (1950), El reino de Dios, arquetipo politico (1964), Burocracia y tecnocracia (1974) y Las transformaciones del Estado moderno (1977). En la actualidad es Presidente del Tribunal Constitucional.

Manuet Ramínez JimÉnez: Doctor en Derecho por la Universidad de Granada, cursó también estudios de ciencia política en las Universidades de Columbia y Stanford (Estados Unidos), y de Derecho constitucional en el Instituto de Estudios Políticos de París. Catedrático de Derecho Político de la Universidad de Zaragoza, es Presidente de la Asociación Española de Ciencia Política. De entre sus numerosas publicaciones cabe destacar los libros Los grupos de presión en la Segunda República dspañola, Nuevas perspectivas de la Ciencia Politica, Las reformas de la Segunda República, España 1939-1975; régimen politico e ideologia, y Ordenamiento constitucional de España (en colaboración con F. Murillo Ferrol).

Luis Morell Ocaña: Pertenece al Cuerpo Técnico de Administración Civil del Estado y es Catedrático de Derecho Administrativo en la Universidad de Extremadura. Pertenece al Consejo de Redacción de esta Revista, y ha publicado numerosos trabajos sobre la Administración central y local española; entre ellos pueden destacarse los titulados Estructuras locales y ordenación del espacio, La deleggción entre entes en el Derecho Públiço español, asi como sus Lecciones de Derecho Administrativo.

Joaquin Tomás Villarnoya: Es Abogado del Estado y Profesor Agregado de Derecho Politico en la Universidad de Valencia. De entre sus libros pueden señalarse El sistema politico del Estatuto Real, Breve historia del constitucionalismo español, El recurso de inconstitucionalidad en España (1931-1936), La formación del Gobierno durante la Segunda República, Proceso constituyente y nueva Constitución. Un análisis critico; y Las fuentes del Derecho en las Comunidades Autónomas. 
Ignacio de Otto y Pardo: Nació en Lugo en 1945. Doctor en Derecho por la Universidad de Barcelona, ha sido Profesor de Derecho Político en la de Santiago de Compostela y de Teoria del Estado en la de Barcelona. Profesor Agregado de Derecho Político en la Universidad de Oviedo, en la actualidad es Letrado del Tribunal Constitucional. Autor de numerosas publicaciones de su especialidad.

José Luis Carro Fernández-Valmayor: Nacido en 1842, es licenciado en Derecho por la Universidad de Santiago y doctor en Derecho por la Universidad de Bolonia, en la que obtuvo el premio «Vittorio Emmanuele II» a la mejor tesis doctoral. Ha ampliado estudios en Francia (Universidad de Toulousse) y Alemania (Universidad de Heidelberg). En la actualidad es Profesor Agregado de Derecho Administrativo en la Universidad de Santiago de Compostela. Autor de numerosos trabajos, fundamentalmente sobre temas como el concepto de acto político, policía, libertad de enseñanza, potestad reglamentaria, etc.

Rafael Gómez-Ferrer Morant: Doctor en Derecho por la Universidad de Bolonia, donde obtuvo el Premio aLuigi Ravá a la mejor tesis en Derecho Público. Es Letrado del Consejo de Estado y Catedrático de Derecho Administrativo de la Universidad de Palma de Mallorca. Secretario de la Asociación Española de Profesores de Derecho Administrativo y del Consejo de Redacción de la Revista Española de Derecho Administrativo. Magistrado del Tribunal Constitucional, es autor de numerosos estudios y trabajos.

Luis Martín Rebollo: Nació en Madrid en 1947. Licenciado en Derecho por la Universidad de Valladolid, se doctoró con premio extraordinario en la de Zaragoza, de la que actualmente es Profesor Adjunto de Derecho Administrativo. De entre sus publicaciones pueden destacarse $E l$ proceso de elaboración de la Ley de lo contencioso-administrativo de 13 de septiembre de 1888 (1975), Aspectos juridicos del trasvase del Ebro (1975, en colaboración) y La responsabilidad patrimonial de la Administración en la Jurisprudencia.

José Antonio Sánchez Mariscal: Nació en Arcos de la Frontera (Cádiz) en 1937. Licenciado en Derecho por la Universidad de Sevilla, pertenece al Cuerpo Técnico de Administración Civil, desempeñando en la actualidad el puesto de Vocal Asesor en la Subsecretaria del Ministerio de la Presidencia.

Victoriano Colodrón Gómez: Licenciado en Derecho, pertenece al Cuerpo Técnico de Administración Civil, Es Subdirector General de Organización y Programación del Ministerio de la Presidencia, y forma parte del Comité de Redacción de esta Revista.

JaIme Nicolás MuñIZ: Nacido en 1947. Es licenciado en Derecho por la Universidad Complutense y licenciado en Ciencias Sociales por la Universidad de Konstanz (República Federal Alemana). Ha sido Secretario de la Revista Española de Investigaciones Sociológicas y Director del Departamento de Documentación del Centro de Estudios Constitucionales. En la actualidad es Letrado del Tribunal Constitucional. 